\title{
Micron-Sized Surface Enhanced Raman Scattering Reporter/Fluorescence Probe Encoded Colloidal Microspheres for Sensitive DNA Detection
}

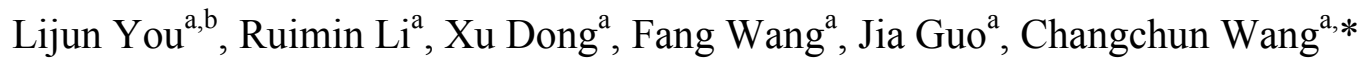




\begin{abstract}
A new type of optical probes, featuring surface enhanced Raman scattering (SERS) and fluorescence spectra dual-mode encoding, has been reported in this article. Based on the uniform micrometer-sized melamine resin/Ag nanoparticles (MRM/Ag-NPs) composite microspheres, the SERS and fluorescent probes were successfully fixed onto the different layers of the MEM/Ag-NPs microspheres, which supported the sensitive DNA detecton. The two spectroscopic methods commonly considered to be contradictive to each other, yet the optical signals were separable in the experiments. The dual-encoding strategy and single microsphere detecton method put the number of available independent codes to be rough the multiple of those available in the two optical detection channels, which increases far more rapidly than the summation of the two channels. As a proof of cencept, the utility of this dual spectrum mode SERS-fluoresecence encoded microsphere (SFEM) was demonstrated in a specific DNA detection using complimentary ssDNA functionalized magnetic beads as the DNA capturing and separation agents. Excellent encoding results were demonstrated from the decoding of the SERS and fluorescence signals of the SFEM. The method appears to be general in scope and we expect that the SERS-fluoresecence encoded microspheres system is applicable to multiplex bioassays of a variety of biomolecules.
\end{abstract}

KEYWORDS: micrometer-sized; melamine resin microsphere; siliver nanoparticles; surface enhanced Raman scattering (SERS); fluoresecence probes; DNA detection; multiplex bioassays 


\section{Introduction}

Rapid, highly sensitive and specific methods for biological molecule detections are of great importance for biological research, clinical studies and disease diagnosis $[1,2]$. While current bioassay techniques allowed single molecular detection in well-controlled laboratory conditions, high throughput analysis of complex biological samples, for example, sequencing the DNA in a biopsy sample in a typical test lab within the clinically relevant time frames, remained a formidable challenge [3-5]. The efficiency of an assay can be measured by the number of samples processed in a given time as well as the number of tests obtained in each of the samples without splitting [6]. In automated labs, the multiplexation approach, i.e. completing multitude tests without increase the sample handling time and the mechanical complexity of the process is a salient new feature in bioanalytical science [1]. Two methods are commonly employed in the high throughput bioassays, namely suspension arrays and planner arrays $[6,7]$.

Compared with planar arrays, encoded microsphere-based suspension assays have significant advantages including more molecular binding sites, fast binding speed, flexibility in target selection, effectively improve the sensitivity and well controlled binding conditions [8-11]. In recent years, a great deal of research effort has been devoted to increasing the reliability and the capacity of microsphere encoding for suspension bead arrays $[2,3]$. Spectral encoding is one of the most important methods for microsphere encoding [8]. This approach incorporates mixtures of luminescent materials such as rare earth emitters $[12,13]$, photonic crystals [14], semiconductor quantum dots [15], or fluorescent dyes [16] that emit light at different wavelengths to generate uniquely identifiable signatures. Micron- and nano-dimensioned optically encodings are known as encoded microspheres. Semiconductor quantum dots and fluorescent dyes based fluorescence encoded microspheres have attracted considerable attention for multiplexed bioassays. Quantum dots (QD) are promising as encoding elements due to their excellent optical properties, such as high quantum yield of photoluminescence, broad excitation spectra, and narrow emission peaks, leading to a variety of applications in analytical chemistry and biochemistry [17,18]. For example, Wang and his co-workers adopted membrane emulsification and solvent evaporation approach for efficient 
preparation of QD barcodes and applied them for multiplexed hepatitis B detection [6]. However, time-consuming preparations, toxicity and chemical instability were recognized, which limited their applications in the corresponding bioanalytical systems[16,19]. In contrast, fluorescent dyes based encoding technology is by far the most popular approach reported in the literature, due to its simplicity in the encoding process, low cost, good assay compatibility and rapidity in signal acquisition [20]. For example, Liu et al. [21] synthesized five polystyrene fluorescent microspheres by the dispersion copolymerization method. They found that the microspheres could be functionalized with amino groups without fluorescence leakage. Except fluorescence spectral encoding, surface-enhanced Raman scattering (SERS) has been used for encoding system and received significant attention in recent years due to its high specificity and low detection limitation. Zhang et al. [22] reported an efficient multiplexed assay strategy to detect single and multi-target DNA using SERS encoding. In the early work, a class of SRES encoded core-shell nanospheres was developed in our group and application for multiplex detections of DNA targets were demonstrated [23].

The number of potential unique codes depends on the number of probes (such as fluorescent dyes, quantum dots and SERS reporters) and the intensities discernable of the signals in the experiment according to the formula: $\mathrm{C}=\mathrm{Nm}-1$ (where $\mathrm{C}$ is the number of codes, $\mathrm{N}$ is the number of intensity levels and $\mathrm{m}$ is the number of probes) [24]. In practice, the number of distinct codes is much less than the theoretical value. For example, Raman spectra of most SERS reporters are in the range of $500-2000 \mathrm{~cm}^{-1}$ and one reporter always emit multiple peaks, thus spectral overlap inevitably occur when several SERS reporters were used for coding, leading to reduced coding capacity. This also happened when the fluorescent probes were used. The coding capacity could be further reduced due to the spectral changes caused by interactions between the fluorescent probes. As the number of the probes and concentrations increased, the interactions between the fluorophores became more complicated, which made it difficult to distinguish the individual codes. To overcome above drawbacks, the fluorescence and SERS dual-mode encoded protocols have been employed [25-27], which could partly resolve the problems. In order to further increase the encoding capacity of the microbeads approach, we developed the micron-sized SERS and fluorescent 
dual spectra encoded microspheres (SFEM) system, using the melamine resin as the microsphere material $[28,29]$. We found that this micron-sized dual-encoded system was observed to have higher encoded capacity and more flexible coding applications. The utility of the SFEM microspheres is demonstrated herein in a DNA detection assay, where the target DNA could be effectively caught by using the complimentary DNA probes on magnetic beads and the SFEM microspheres.

\section{Materials and methods}

\subsection{Materials}

Melamine, aqueous formaldehyde solution (37\%), formic acid, silver nitrate $\left(\mathrm{AgNO}_{3} \geq\right.$ 99.8\%), aqueous ammonia solution $\left(\mathrm{NH}_{3} \cdot \mathrm{H}_{2} \mathrm{O}, 28 \%\right)$, 4-hydroxythiophenol (HBT $>98 \%$ ), tetraethoxylsilane (TEOS $>98 \%$ ), and anhydrous ethanol were purchased from Shanghai Chemical Reagent Co. Ltd. Butylamine (purity $\geq 99 \%$ ), 4-aminobenzenethiol (ABT, purity $\geq$ 98\%), 4-chlothiophenol (CBT purity $\geq 98 \%$ ), 5, 5'-dithiobis-(2-nitrobenzoic acid) (DTNB, purity $\geq 99 \%$ ), succinic anhydride (SA), phloxine $\mathrm{B}\left(\mathrm{C}_{20} \mathrm{H}_{2} \mathrm{Br}_{4} \mathrm{Cl}_{4} \mathrm{Na}_{2} \mathrm{O}_{5}\right)$, fluorescein 5(6)-isothiocyanate $\left(\mathrm{C}_{21} \mathrm{H}_{11} \mathrm{NO}_{5} \mathrm{~S}\right)$, aminopropyltriethoxysilane and tetramethylthiuram disulfide (analytical grade) were purchased from the Aladdin Chemical Reagent Co. Ltd. Chloride hexahydrate $\left(\mathrm{FeCl}_{3} \cdot 6 \mathrm{H}_{2} \mathrm{O}\right)$, ammonium acetate $\left(\mathrm{NH}_{4} \mathrm{Ac}\right)$, ethyleneglycol (EG), N,N-dimethylformamide (DMF), anhydrous ethanol and 1-ethyl-3-(3-dimethyllaminopropyl) carbodiimide hydrochloride (EDC, 98.5\%) were got from Sinopharm Chemical Reagent Co. Ltd. 3-Methacryloxypropyltrimethoxysilane (MPS) was obtained from Sigma-Aldrish Co. Ltd. The oligonucleotides were purchased from Sango Biotech (Shanghai) Co. Ltd. and purified using high performance liquid chromatography. All glass slides were cleaned by ultrasonication in absolute ethanol before the experiments. All chemicals were used as received without further purification. Purified water (Millipore) of resistivity greater than $18.0 \mathrm{M} \Omega \mathrm{cm}$ was used in all experiments.

\subsection{Synthesis of fluorescent melamine-formaldehyde microspheres}

The fluorescent melamine resin microspheres (MRM) were prepared by a precipitation polymerization. For a typical synthesis, a solution of $120 \mathrm{~mL}$ in volume containing $1.8 \mathrm{~g}$ 
formaldehyde was prepared and $1.25 \mathrm{~g}$ melamine was added while stirring. The reaction mixture was heated to $70{ }^{\circ} \mathrm{C}$ for $30 \mathrm{~min}$, then $0.01 \mathrm{~mL}$ formic acid was added into the reaction solution to catalyze the polycondensation reaction, meanwhile, fluorescent probes (Phloxine B and Fluorescein 5(6)-isothiocyanate) were injected in. After 2 hours, the suspension was allowed to site and cool to room temperature. Finally, the supernatant was removed by centrifugation and the obtained MRM microspheres were washed with water and ethanol for 3 times, respectively, and dried under vacuum at $50{ }^{\circ} \mathrm{C}$ for $4 \mathrm{~h}$.

\subsection{Preparation of melamine resin/Ag nanoparticles (MRM/Ag-NPs ) composite microspheres}

The deposition of Ag nanoparticles (Ag-NPs) onto the MRM microspheres was carried out as the following procedure: $5 \mathrm{mg}$ MRM microspheres were dispersed in a $20 \mathrm{~mL} \mathrm{AgNO}_{3}$ ethanol solution followed by addition of butylamine. The mixture was treated by ultrasonication for $2 \mathrm{~min}$ and incubated for $120 \mathrm{~min}$ at $50{ }^{\circ} \mathrm{C}$ in a shaker with vigorous shaking (200 r/min). In this process, excessive amount of butylamine was used to make sure the $\mathrm{AgNO}_{3}$ be reduced completely. After the reaction, the MRM/Ag-NPs composite microspheres were rinsed with ethanol under sonication and re-dispersed in absolute ethanol for future use.

\subsection{Synthesis of SERS-fluorescent combined encoded microspheres (SFEM)}

The as-prepared MRM/Ag-NPs composite microspheres were dispersed in a mixture composed of $10^{-3} \mathrm{~mol} / \mathrm{L}$ Raman reporter's (ABT, CBT, DTNB and HBT) ethanol solution by sonication, then reacted at room temperature for $1.5 \mathrm{~h}$. The resultant was washed several times with anhydrous ethanol to remove excess Raman reporters. Next, $20 \mathrm{mg}$ of these microspheres were dispersed in a mixture of $18 \mathrm{~mL}$ water, $60 \mathrm{~mL}$ ethanol, and $2 \mathrm{~mL}$ ammonia solution. The mixture was reacted under stirring for $6 \mathrm{~h}$ followed by addition of 0.3 g TEOS, then the SERS-fluorescent joint encoded microspheres (SFEM) were obtained. The as prepared SFEM were washed repeatedly with ethanol and water to eliminate excess reagent. Finally the sample was dispersed in water for further use.

\subsection{Conjugation of SFEM with probe DNA strands (denoted as SFEM-p-DNA)}

$20 \mathrm{mg}$ SFEM microspheres and $2 \mathrm{~mL}$ aminopropyltriethoxysilane were feed into a solution 
composed of $18 \mathrm{~mL}$ water, $60 \mathrm{~mL}$ ethanol and $1 \mathrm{~mL}$ ammonia solution. After a brief sonication, the mixture was allowed to react at room temperature for $12 \mathrm{~h}$. The reaction mixture was then centrifuged, washed by ethanol and water alternately for three times, and dried under vacuum at $50{ }^{\circ} \mathrm{C}$. The amino-modified SFEM was allowed to react with succinic anhydride $(50 \mathrm{mg}$ ) in DMF $(15 \mathrm{~mL})$ for $24 \mathrm{~h} \mathrm{[30]}$. The resulting reaction mixture was centrifuged and the carboxy-modified SFEM obtained. The probe DNA strands with amino groups at the $3^{\prime}$ end were reacted with the carboxy-modified SFEM in the presence of EDC to form SFEM modified probe DNA strands [31]. The product was denoted as SFEM-p-DNA. Typically, $2 \mathrm{mg}$ carboxy-modified SFEM and $2 \mathrm{~mL}$ EDC aqueous solution $(10 \mathrm{mg} / \mathrm{mL}$ ) were mixed with $2 \mathrm{~mL}$ phosphate buffer solution (PBS, $10 \mathrm{mM}$, $\mathrm{pH}$ 7.4) containing $2 \mu \mathrm{mol} / \mathrm{L}$ probe DNA. The resulting mixture was incubated at room temperature for $12 \mathrm{~h}$. The reaction mixture was centrifuged (at $2000 \mathrm{r} / \mathrm{min}$ ) and washed by PBS $(5 \mathrm{~mL}, 10 \mathrm{mM}$ $\mathrm{pH}$ 7.4) for three times. The obtained SFEM-p-DNA were re-dispersed in $2 \mathrm{~mL}$ solution of $\mathrm{NaCl}(0.6$ M) and PBS (10 mM, pH 7.4) and stored at $4{ }^{\circ} \mathrm{C}$. With three different target DNAs, three corresponding SFEM-p-DNA were obtained.

\subsection{Conjugation of magnetic composite nanospheres with capture DNA strands (denoted as Mag-c-DNA)}

The synthesis of polyacrylic acid (PAA) coated $\mathrm{Fe}_{3} \mathrm{O}_{4}$ magnetic composite nanospheres $\left(\mathrm{Fe}_{3} \mathrm{O}_{4} / \mathrm{PAA}\right)$ was carried out as following: first, the $\mathrm{Fe}_{3} \mathrm{O}_{4}$ magnetite nanocrystal clusters was prepared through a solvothermal reaction. Before coated by PAA, the $\mathrm{Fe}_{3} \mathrm{O}_{4}$ magnetite nanocrystal clusters were modified with 3-(trimethoxysilyl)propyl methacrylate. Specifically, $300 \mathrm{mg} \mathrm{Fe}_{3} \mathrm{O}_{4}$ magnetite nanocrystal clusters was mixed with $40 \mathrm{~mL}$ of ethanol, $9 \mathrm{~g}$ of deionized water, and $1.5 \mathrm{~g}$ of 3-(trimethoxysilyl)propyl methacrylate and ulrtrasonited to form a brownish dispersion. The dispersion was transferred into a three-necked flask and $2 \mathrm{~mL}$ of aqueous ammonia solution was injected in, then the dispersion was stirred vigorously at $70^{\circ} \mathrm{C}$ for $24 \mathrm{~h}$ to combine vinyl groups onto the surface of $\mathrm{Fe}_{3} \mathrm{O}_{4}$ clusters. After reaction, the product was washed with ethanol and deionized water three times, isolated by magnetic and dried in vacuum. The $\mathrm{Fe}_{3} \mathrm{O}_{4} / \mathrm{PAA}$ nanospheres were synthesized by distillation precipitation polymerization [32]. Typically, $100 \mathrm{mg}$ vinyl-modified $\mathrm{Fe}_{3} \mathrm{O}_{4}$ nanocrystal clusters were dispersed in $100 \mathrm{~mL}$ acetonitrile in a single-necked flask, then $400 \mathrm{mg}$ acrylic acid, $100 \mathrm{mg} \mathrm{N}$, N'-methylene bisacrylamide and $10 \mathrm{mg}$ azobisisobutyronitrile were mixed. 
The flask was attached with a fractionating column, Liebig condenser and a receiver. The mixture was heated by oil bath from room temperature to the boiling state within $30 \mathrm{~min}$ and the reaction was ended after about a $50 \mathrm{~mL}$ acetonitrile was distilled from the mixture within $1 \mathrm{~h}$. The obtained $\mathrm{Fe}_{3} \mathrm{O}_{4} / \mathrm{PAA}$ composite nanospheres were collected by magnet and washed with ethanol. Last, $\mathrm{Fe}_{3} \mathrm{O}_{4} / \mathrm{PAA}$ composite nanospheres and capture DNA strands with amino groups at the $5^{\prime}$ end were covalently linked using the carbodiimide method to obtain the magnetic capture DNA (Mag-c-DNA). Specifically, $4 \mathrm{mg} \mathrm{Fe}_{3} \mathrm{O}_{4} / \mathrm{PAA}$ was dispersed in an aqueous solution of EDC $\left(4 \mathrm{~mL}, 10 \mathrm{mg} / \mathrm{mL}^{-1}\right)$, then a solution of the capturing DNA strand $(2 \mu \mathrm{mol} / \mathrm{L}$, in $4 \mathrm{~mL}$ PBS, $10 \mathrm{mM}, \mathrm{pH}$ 7.4) was added and the mixture was incubated for $12 \mathrm{~h}$ at room temperature. The resulting Mag-c-DNA was washed by PBS (5 mL, $10 \mathrm{mM} \mathrm{pH} \mathrm{7.4)} \mathrm{several} \mathrm{times} \mathrm{and} \mathrm{then} \mathrm{dispersed} \mathrm{in} \mathrm{a} \mathrm{PBS} \mathrm{solution} \mathrm{(} 2 \mathrm{~mL}, 0.6 \mathrm{M} \mathrm{NaCl}$, $10 \mathrm{mM}$ PBS, $\mathrm{pH}$ 7.4) and stored at $4{ }^{\circ} \mathrm{C}$ for further use.

\subsection{Detection of target DNA strands (denoted as t-DNA)}

The sandwich hybridization assay was adopted for the detection of the t-DNA [33]. The hybridization reaction was carried out as the following: First, t-DNA solution $\left(100 \mu \mathrm{L}, 10^{-10} \mathrm{~mol} / \mathrm{L}\right)$ and SFEM-p-DNA solution $(600 \mu \mathrm{L}, 0.45 \mathrm{mg})$ were mixed and incubated at $25^{\circ} \mathrm{C}$ for $4 \mathrm{~h}$ under shaking; then a Mag-c-DNA solution ( $300 \mu \mathrm{L}, 0.2 \mathrm{mg}$ ) was added dropwise into the above mixture and incubated for another $4 \mathrm{~h}$ under shaking. Afterward, the resultant complexes were collected by magnetic separation, washed with PBS solution and detected by fluorescence and SERS spectra. DNA solution without the complimentary t-DNA was used as the negative control for the above experiments.

\subsection{Characterization}

Field-emission scanning electron microscopy (SEM) was performed on a Hitachi S-4800. The scanning electron microscope was at an accelerating voltage of $20 \mathrm{kV}$. Fluorescence spectra detection were measured in solution and carried out by a Shimadzu RF-5301PC fluorescence spectrophotometer using $488 \mathrm{~nm}$ as the excitation wavelength. SERS spectra were recorded using the Invia Reflex by Renishaw with $632.8 \mathrm{~nm}$ laser excitation (He-Ne laser, $17 \mathrm{mw}$ ). The SERS measurements were carried out by focusing the laser on a single microsphere of the samples. Fourier transform infrared spectra (FT-IR) were determined on a NEXUS-470 FT-IR spectrometer. Magnetic characterization was carried out with a VSM on a Model 6000 physical property measurement 
system (Quantum, USA) at $300 \mathrm{~K}$. Fluorescence images were obtained using OLYMPUS U-UCD8A microscope. Transmission electron microscopy (TEM) images were taken on a JEM-2100F transmission electron microscope at an accelerating voltage of $200 \mathrm{kV}$. Zeta potential measurements were conducted by dynamic light scattering (DLS) with a ZEN3600 (Malvern, UK) Nano ZS instrument.

\section{Results and discussion}

\subsection{Preparation and characterization of SERS-fluorescent encoded microspheres (SFEM)}

The synthetic procedure of the designed SFEM was illustrated in Scheme 1. The uniform and monodispersed fluorescent melamine resin microspheres (MRM) were synthesized by polymerization of melamine and formaldehyde in aqueous solutions.

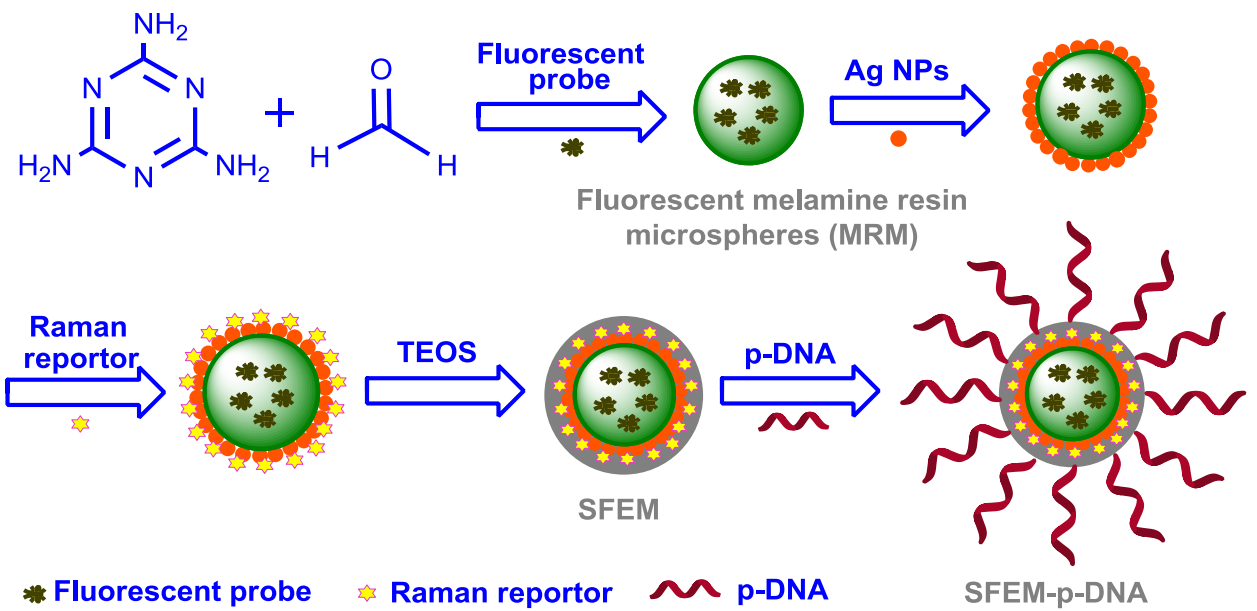

Scheme 1 Synthetic procedure of the SERS-fluorescence encoded microspheres (SFEM) and probe DNA modified SFEM (SFEM-p-DNA).

Fluorescein 5(6)-isothiocyanate (FITC) and phloxine B (PHB) were used to encode the microspheres. The FITC modified MF microsphere (F-MRM), the PHB modified MF microsphere (P-MRM), and the FITC and PHB modified MF microsphere (FP-MRM) were fabricated. Fluorescence emission spectra of the three types of the microspheres were shown in Figure 1. The F-MRM and P-MRM probes were encoded by emission peaks at $520 \mathrm{~nm}$ and $572 \mathrm{~nm}$, respectively. Two emission peaks of the FP-MRM microspheres at $520 \mathrm{~nm}$ and $572 \mathrm{~nm}$ were encoded by 
controlling FITC and PHB ratios (1:1.8 g/g, 1:15 g/g, 1:35 g/g and 1:50 g/g). For the FP-MRM microspheres, the emission peaks could be distinguished clearly and the intensity of the emission could also be adjusted by controlling the dosage ratios of FITC and PHB.

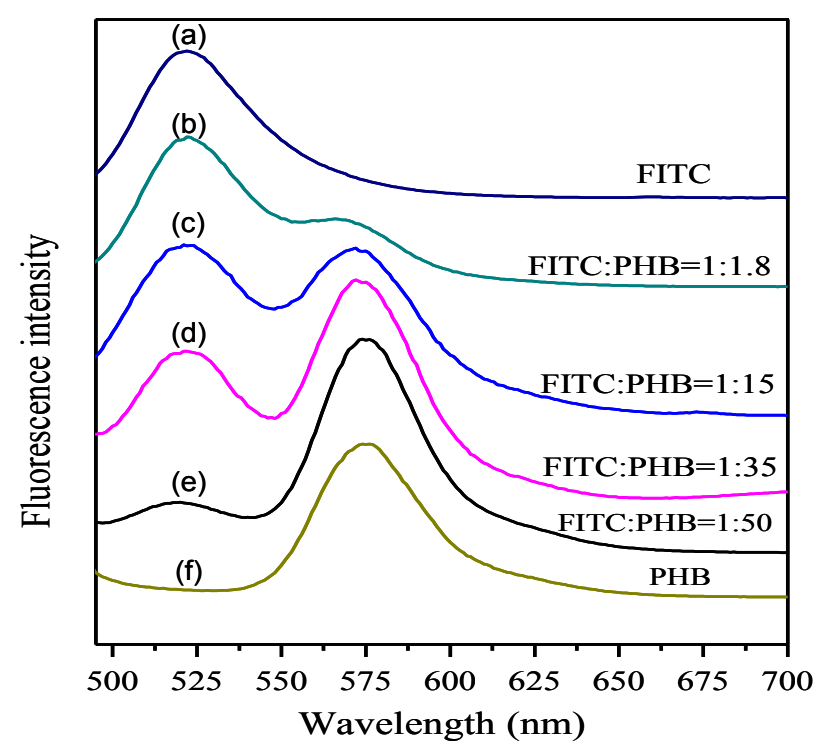

Figure 1 The fluorescence spectra of (a) F-MRM, (b)-(e) FP-MRM prepared with different dosage ratio of FITC and PHB (g/g), and (f) P-MRM fluorescent microspheres. The excitation wavelength was $488 \mathrm{~nm}$.

The SEM and Fluorescence images of F-MRM were shown in Figure 2. For the SERS encoding, F-MRM/Ag-NPs microspheres were prepared by depositing Ag-NPs on the surface of the F-MRM microspheres. The F-MRM/Ag-NPs microspheres were modified by single SERS reporters ABT, CBT, DTNB, HBT and double reporters HBT-DTNB, HBT-CBT, ABT-CBT, CBT-DTNB, respectively. The SEM images of F-MRM/Ag-NPs modified by DTNB (F-MRM/Ag(DTNB)) was shown in Figure 2(c). Compared with Figure 2(a), it could be observed that the surface of F-MRM/Ag(DTNB) was very rough, indicating successful coating of Ag-NPs. The F-MRM/Ag(DTNB) was coated a silica shell using a modified Stöber-based approach, the encapsulating of silica shell was designed to protect the Ag-NPs and SERS reporters. Meanwhile, with a silica layer, it was considered to be beneficial for further surface modifications of the encoded microspheres. The SEM images of the $\mathrm{SiO}_{2}$ encoded microspheres (F-MRM/Ag(DTNB)/SiO 2 ) was shown in Figure 2(d). As it was indicated by the images of F-MRM/Ag(DTNB), the surfaces of the 
F-MRM $/ \mathrm{Ag}(\mathrm{DTNB}) / \mathrm{SiO}_{2}$ became smooth which indicated a thin silica layer on their surfaces. Similarly, the PHB and FITC/PHB (1:15 g/g) encoded microspheres also have been prepared, they were denoted as P-MRM/Ag(HBT)/SiO ${ }_{2}$ and FP-MRM/Ag(HBT-DTNB $) / \mathrm{SiO}_{2}$, and the related properties were also chareacterized (Figure S1 and S2 in the supporting information).

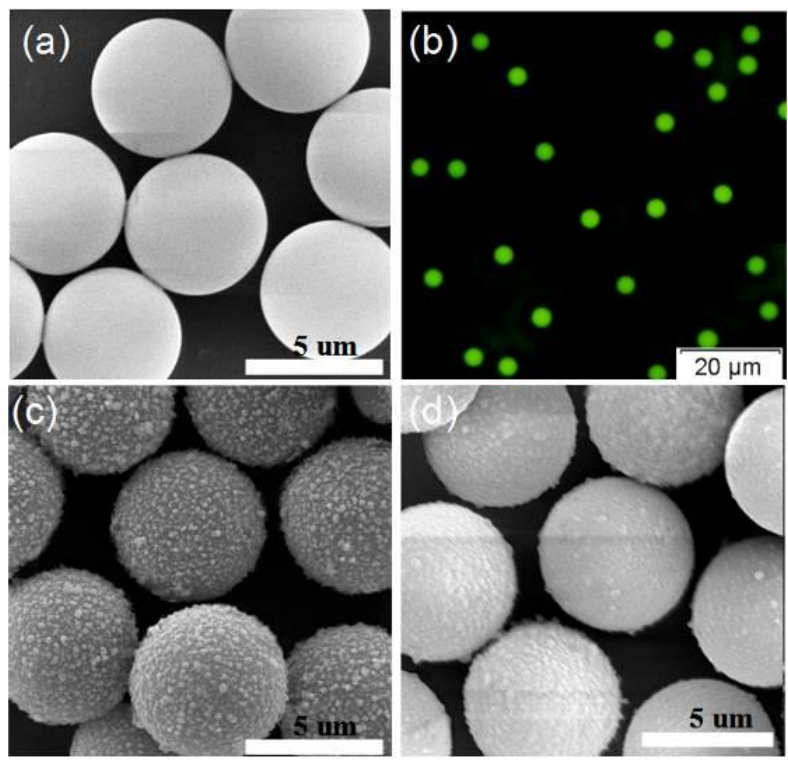

Figure 2 (a) SEM image of F-MRM microspheres; (b) Fluorescence photograph of F-MRM microspheres; (c) SEM image of F-MRM/Ag(DTNB) microspheres; (d) SEM image of F-MRM/Ag (DTNB) $/ \mathrm{SiO}_{2}$ microspheres.

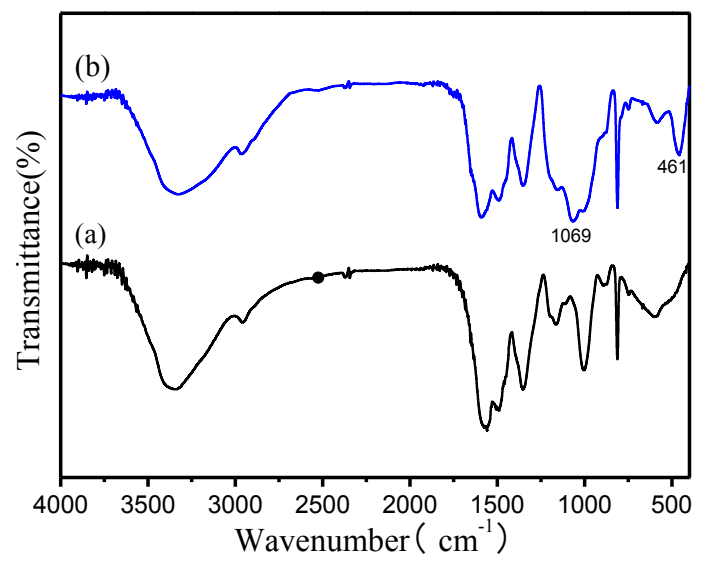

Figure 3 FT-IR spectra of (a) FP-MRM/Ag(HBT-DTNB) and (b) FP-MRM/Ag(HBT-DTNB)/SiO microspheres. The mass ratio of HBT to DTNB was 3:1.

In order to confirm the coating of the $\mathrm{SiO}_{2}$ shell, FP-MRM/Ag(HBT-DTNB) and FP-MRM/Ag(HBT-DTNB)/SiO 2 were characterized by FT-IR spectra shown in Figure 3(a). The 
infrared absorption bands were dominated by those from the MF microspheres, because the amount of HBT and DTNB was only a small fraction of the base material. The strong broad adsorption bands at $3497-3195 \mathrm{~cm}^{-1}$ is derived from the overlapped stretching vibrations of the $-\mathrm{NH}_{2}$ groups and the hydroxyl groups; the $\mathrm{C}-\mathrm{H}$ stretching vibration of methylene group appears at $2954 \mathrm{~cm}^{-1}$; the bands at $1565 \mathrm{~cm}^{-1}$ and $1494 \mathrm{~cm}^{-1}$ were assigned to the stretching vibrations of $\mathrm{C}=\mathrm{N}$ bonds; the peak at 1353 $\mathrm{cm}^{-1}$ was assigned to the stretching modes of the $\mathrm{C}-\mathrm{N}$ bonds; the vibrations of ether $\mathrm{C}-\mathrm{O}$ bonds appeared at $1169 \mathrm{~cm}^{-1}$ and $1014 \mathrm{~cm}^{-1}$; moreover, peaks at $887 \mathrm{~cm}^{-1}$ and $809 \mathrm{~cm}^{-1}$ were assigned to the vibrations of the framework breathing modes of the triazine ring. For FP-MRM/Ag(HBT-DTNB)/ $/ \mathrm{SiO}_{2}$, the new bands at $1069 \mathrm{~cm}^{-1}$ (Si-O-Si asymmetric stretching vibration) and $461 \mathrm{~cm}^{-1}$ (Si-O-Si symmetric stretching vibration) in Figure 3(b) were derived from $\mathrm{SiO}_{2}$ shells, suggesting that $\mathrm{SiO}_{2}$ had been coated onto the surface of FP-MRM/Ag(HBT-DTNB).

\subsection{SERS-fluorescence characterization and encoding capacity of SFEM.}

The SERS spectra of the SFEM containing ABT, CBT, DTNB, HBT, ABT-CBT (1:2 by weight, the same in this article), HBT-CBT (1:1), CBT-DTNB (1:3) and HBT-DTNB (3:1) were shown in Figure 4. These SFEM were all marked with FITC as fluorescent probe. It could be observed that the SERS characteristics of the reporters retained well after being coated silica shell. In Figure 4a, the SERS spectrum of ABT was dominated by two groups of the peaks, one at 1074, 1141, $1187 \mathrm{~cm}^{-1}$ and the other at 1389,1435 , and $1573 \mathrm{~cm}^{-1}$. The SERS signal of CBT was characterized by peaks at $335,539,1570 \mathrm{~cm}^{-1}$ and an envelope between 1038 to $1116 \mathrm{~cm}^{-1}$. SERS signal of DTNB was characterized by peaks at 1063,1152, 1336 and $1554 \mathrm{~cm}^{-1}$. The characteristic peak of HBT was at $387,1077,1492$ and $1599 \mathrm{~cm}^{-1}$. When the mixture of ABT-CBT (weight ratio is 1:2) was used as the SERS agent (Figure 4b), SERS peaks at 1141, 1187, 1389, 1435, $1573 \mathrm{~cm}^{-1}$ were derived from ABT, while $335,539 \mathrm{~cm}^{-1}$ and the palm like group peaks at 1038 to $1116 \mathrm{~cm}^{-1}$ derived from CBT can be observed simultaneously. When HBT-CBT (1:1) was used as the SERS agent, characteristic peaks at 335 and $387 \mathrm{~cm}^{-1}$ can be observed clearly. For CBT-DTNB (1:3), characteristic peaks at 335, 539, $1152,1336 \mathrm{~cm}^{-1}$ and a palm like group peaks at 1038 to $1116 \mathrm{~cm}^{-1}$ derived from CBT were observed. When HBT-DTNB (3:1) was used as the SERS agent, signal peaks at 1554 and $1599 \mathrm{~cm}^{-1}$ can be observed simultaneously. The above results indicated that the eight SFEM can be recognized by their 
distinguished SERS spectral signals. It indicated the fluorescent and SERS jointed way of encoding was available. Moreover, the fluorescence spectra of the as-prepared SFEM encoded with FITC, PHB and FITC-PHB (1:15) as the fluorescence probes and DTNB as SERS reporter were measured (Figure S3). It can be clearly observed that the SFEM with FITC-PHB (1:15) exhibited a well resolved dual fluorescence emission at 520 and $572 \mathrm{~nm}$, indicating that the SERS-multicolor fluorescent jointed way of encoding is available.
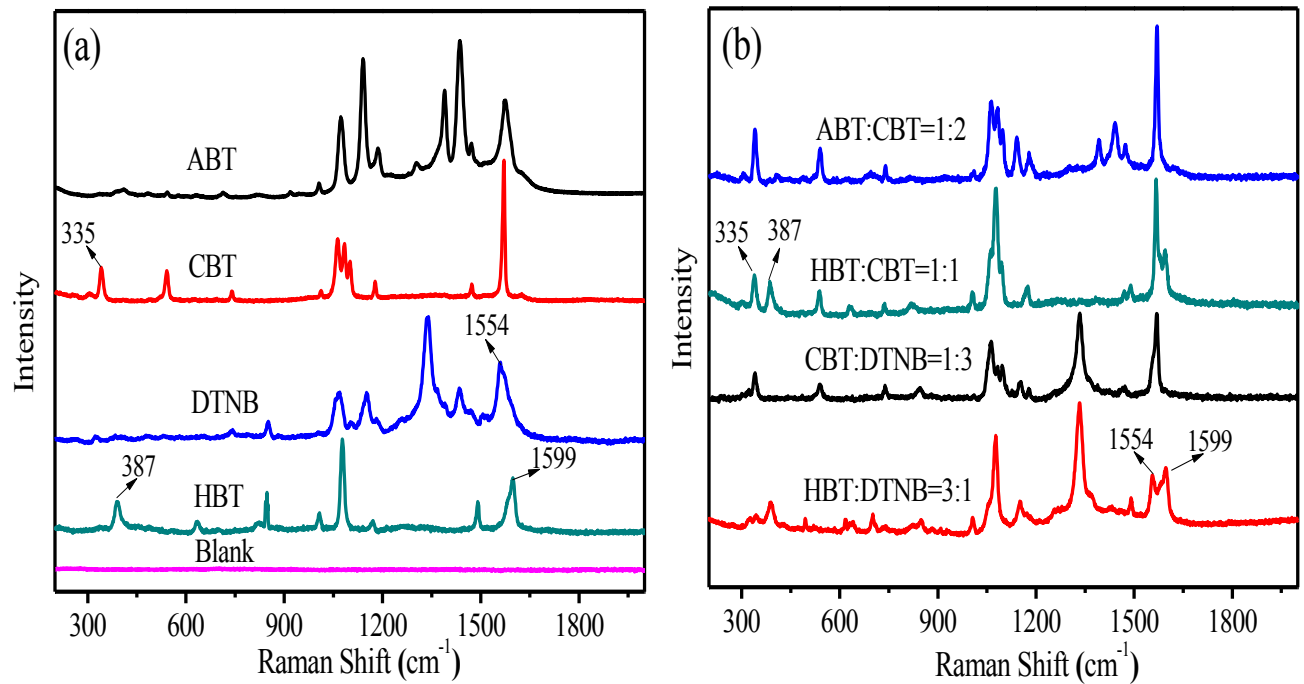

Figure 4 SERS spectra of the SERS-fluorescence encoded microspheres with (a) ABT, CBT, DTNB, and HBT; (b) ABT-CBT (weight ratio 1:2), HBT-CBT (weight ratio 1:1), CBT-DTNB (weight ratio 1:3), HBT-DTNB (weight ratio 3:1) as the SERS reporters. FITC was used as fluorescent probe.

Two fluorescent probes (FITC and PHB) and two SERS reporters (HBT and CBT) were used to prepare SFEM and the encoding capacity of the resulting SFEM was evaluated. A total of 15 types of SFEM were fabricated with distinguished optical spectral signals. According to their distinguished SERS and fluorescence signal, fifteen codes were achieved and these codes were marked by a binary way (Figure S4). In contrast, only six encodings possibilities were possible if two fluorescence and two SERS probes were used separately. The dual mode encoding system allowed multiplexing of the two spectra channels in terms of the number of the probes in each channels, leading to geometric serial increase of the possibilities. In the above example, fifteen codes were achieved using two fluorescence and two SERS agents. Many other fluorescence probes and SERS reporters can be used in SERS-fluorescence combined system with distinctive fluorescence and SERS signals. Therefore, the number of codes can be increased greatly by increasing the number of different fluorescence 
probes and SERS reporters. Moreover, the SERS reporters and fluorescent probes were fixed on two different layers in the novel SFEM. This process was found to be controllable and straight forward synthesis. In addition, by taking the fluorescence and SERS spectra in two optical channels to avoid spectral overlaps, the decoding processes were straight for a large pool of SFEM probes. Besides the qualitative spectral information and isolated microsphere detection [28], the discernible intensities of the fluorescence and SERS signals could also be used for increasing the coding capacity in this dual mode optical encoding system to further increased the encoding capacity of the system.

\subsection{Conjugation of SFEM with probe DNA strand (SFEM-p-DNA) and preparation of magnetic capture DNA (Mag-c-DNA)}

F-MRM/Ag(DTNB)/ $/ \mathrm{SiO}_{2}, \quad$ P-MRM/Ag(HBT) $/ \mathrm{SiO}_{2}$ and FP-MRM/Ag(HBT-DTNB) $/ \mathrm{SiO}_{2}$ were utilized to fabricate SFEM-p-DNA. Fluorescence and SERS spectra of the three SFEM were presented in Figure 5. The preparation procedure was shown in Scheme 1 (last step). Firstly, all of SFEMs were modified with aminopropyltriethoxysilane. Before modification, the zeta potential of $\mathrm{SiO}_{2}$ shell was negative (see Table S1). After amino group modification, the zeta potential became positive and all were above $36 \mathrm{mV}$, indicating that the SFEM microspheres were successfully modified by the amino groups. Then the carboxyl modification step was carried out. After reacted with succinic anhydride, the zeta potentials of the SFEMs turned to negative again and were below $-25 \mathrm{mV}$, implying the carboxyl groups were conjugated to the surfaces of the SFEMs. At last, the SFEMs were conjugated with three probing DNA strands (p-DNA), 3' $\mathrm{NH}_{2}\left(\mathrm{~A}_{10}\right)$ AGAAAGAGGAGTTAA, 3' $\mathrm{NH}_{2}\left(\mathrm{~A}_{10}\right)$ TGCATCCA-GGTCATG and 3 ' $\mathrm{NH}_{2}$ $\left(\mathrm{A}_{10}\right)$ TACCACATCATCCAT, respectively. The oligonucleotide sequences of the three SFEM-p-DNA were listed in Table 1.

Table 1 Oligonucleotide sequences of SFEM-p-DNA, Mag-c-DNA and t-DNA

\begin{tabular}{|c|c|c|c|}
\hline System & SFEM-p-DNA & Mag-c-DNA & $\mathrm{t}$-DNA \\
\hline \multirow{2}{*}{ I } & FP-MRM/Ag(HBT-DTNB)/SiO ${ }_{2}-3^{\prime} \mathrm{NH}-$ & $\mathrm{Fe}_{3} \mathrm{O}_{4}-5^{\prime} \mathrm{NH}\left(\mathrm{A}_{10}\right) \mathrm{AAC}$ & 5’ATGGTGTAGTAGGTATAT \\
\hline & $\left(\mathrm{A}_{10}\right)$ ACCACATCATCCAT & CG AAAGTCAATA & TGACTTTCGGTT \\
\hline II & F-MRM/Ag(DTNB $) / \mathrm{SiO}_{2}-3^{\prime} \mathrm{NH}-$ & $\mathrm{Fe}_{3} \mathrm{O}_{4}-5^{\prime} \mathrm{NH}\left(\mathrm{A}_{10}\right) \mathrm{AAT}$ & 5’TCTTTCTCСТCAATTAGG \\
\hline
\end{tabular}


III

P-MRM/Ag(HBT)/SiO ${ }_{2}-3$ 'NH-

$\left(\mathrm{A}_{10}\right)$ TGCATCCAGGTCATG
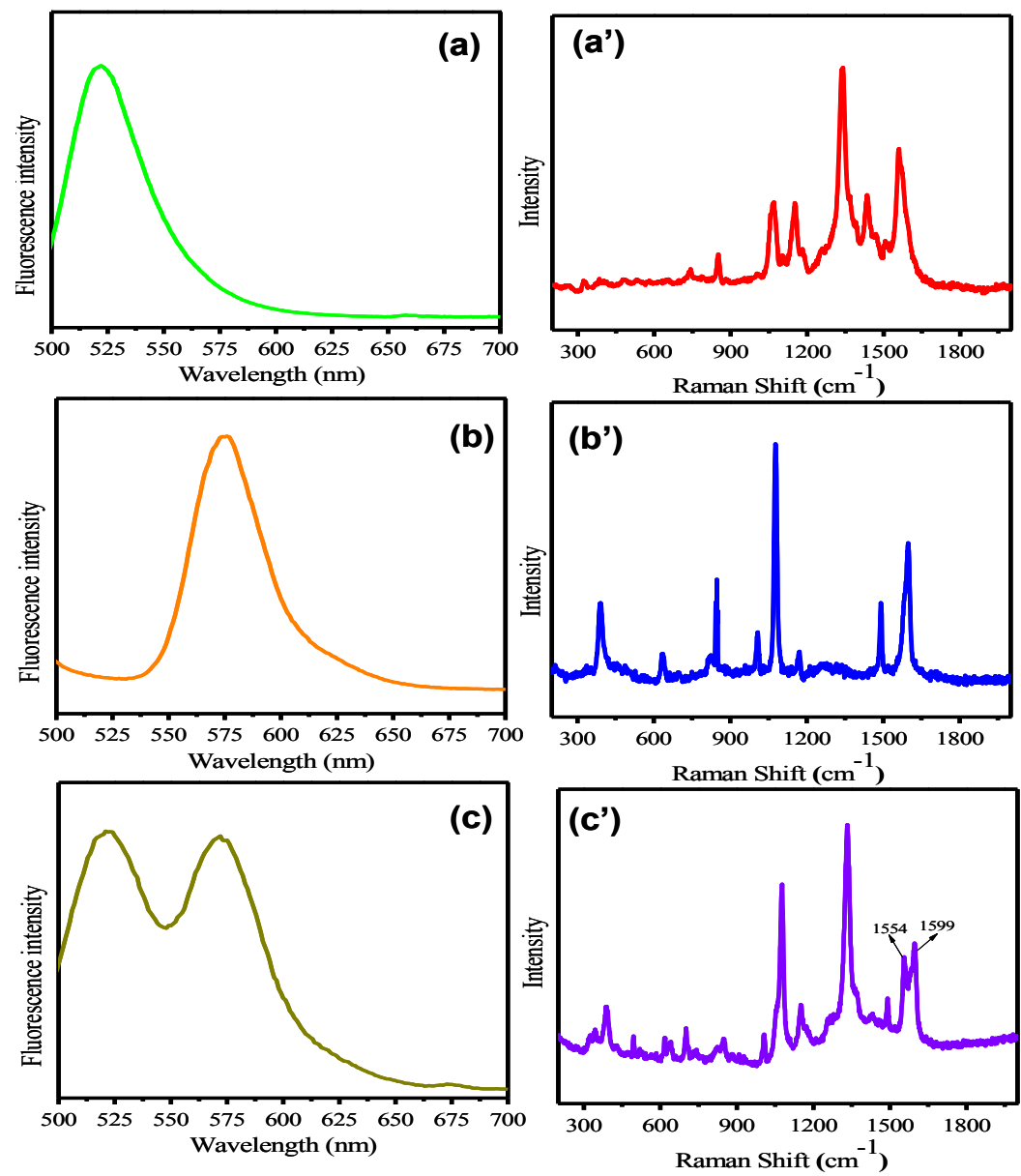

Figure 5. Fluorescence and SERS spectra of F-MRM/Ag(DTNB)/SiO 2 (a, a'), P-MRM/ $\mathrm{Ag}(\mathrm{HBT}) / \mathrm{SiO}_{2}\left(\mathrm{~b}, \mathrm{~b}^{\prime}\right)$, and FP-MRM/Ag(HBT- DTNB)/SiO 2 (c, c').

The capture DNA (c-DNA) modified $\mathrm{Fe}_{3} \mathrm{O}_{4} / \mathrm{PAA}$ nanocomposite microspheres (Mag-c-DNA) was prepared for the easy separation process in the detection system. The TEM of $\mathrm{Fe}_{3} \mathrm{O}_{4}$ and $\mathrm{Fe}_{3} \mathrm{O}_{4} / \mathrm{PAA}$ are shown in Figure 6. The size of the uniform $\mathrm{Fe}_{3} \mathrm{O}_{4}$ and $\mathrm{Fe}_{3} \mathrm{O}_{4} / \mathrm{PAA}$ was $200 \mathrm{~nm}$ and $300 \mathrm{~nm}$, receptively. The $\mathrm{Fe}_{3} \mathrm{O}_{4} / \mathrm{PAA}$ was thus coated by PAA with a thickness of about $50 \mathrm{~nm}$. The FT-IR spectra, TGA and VSM characterization also confirmed the PAA coating (Figure S5). The Mag-c-DNA was prepared through $\mathrm{Fe}_{3} \mathrm{O}_{4} / \mathrm{PAA}$ covalently reacted with the amino groups of the 
c-DNA strands at the $5^{\prime}$ end using the carbodiimide method. Specifically, 4 mg of $\mathrm{Fe}_{3} \mathrm{O}_{4} / \mathrm{PAA}$ was dispersed in $4 \mathrm{~mL}$ of EDC aqueous solution $(10 \mathrm{mg} / \mathrm{mL}$ ), then $4 \mathrm{~mL}$ of $10 \mathrm{mM} \mathrm{PBS}(\mathrm{pH} 7.4)$ solution with c-DNA strands $(2 \mu \mathrm{mol} / \mathrm{L})$ was added and the mixture was incubated for $12 \mathrm{~h}$ at room temperature. The obtained Mag-c-DNA was separated by magnet and washed by $10 \mathrm{mM}$ PBS (pH 7.4) several times and then dispersed in $2 \mathrm{~mL}$ of $0.6 \mathrm{M} \mathrm{NaCl} 10 \mathrm{mM} \mathrm{PBS} \mathrm{(pH} \mathrm{7.4)} \mathrm{and} \mathrm{stored} \mathrm{at} 4{ }^{\circ} \mathrm{C}$ prior to use. In ore experiment, three kinds of Mag-c-DNA were obtained. The oligonucleotide sequences of the obtained Mag-c-DNA were listed Table 1.
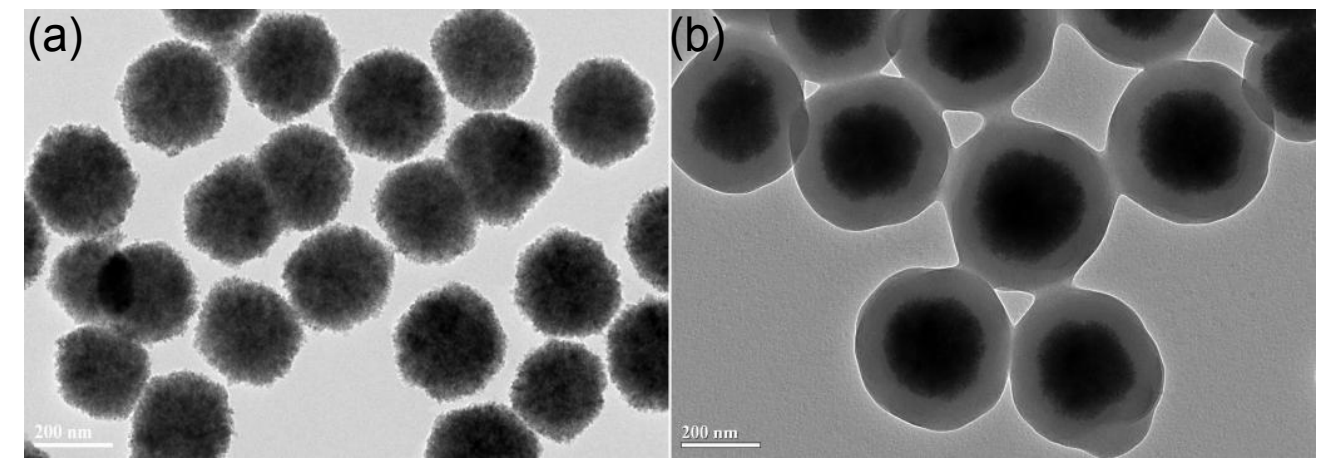

Figure 6. TEM images of (a) $\mathrm{Fe}_{3} \mathrm{O}_{4}$ and (b) $\mathrm{Fe}_{3} \mathrm{O}_{4} / \mathrm{PAA}$ composite microspheres for Mag-c-DNA preparation.

\subsection{Detection of Target DNA Strands (denoted as t-DNA)}

The sandwich hybridization assay was adopted to demonstrate the utility of the multiplexed encoding microsphere system for the detection of the t-DNA [33]. The detection procedure was shown in Scheme 2. Because the 3' end of t-DNA paired with the 5' end of SFEM-p-DNA and its 5' end paired with 3' end of Mag-c-DNA, the SFEM-p-DNA, t-DNA and Mag-c-DNA could form sandwich structures through hybridization between complementary sequences. The sandwich hybridization structure could be quickly separated by a magnet due to the magnetic response of Mag-c-DNA and be identified by fluorescence and SERS derived from SFEM-p-DNA. Moreover, the specific complementary base-pairing reactions could guarantee the specificity and high accuracy of the detection results. 
(a)

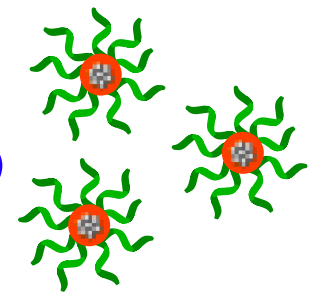

Magnetic microspheres with capture DNA (Mag-c-DNA)

(b)

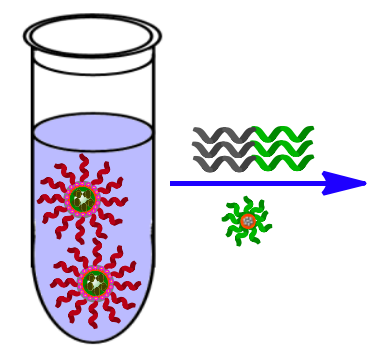

SFEM-p-DNA

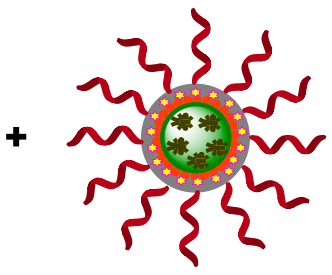

SERS-fluorescence encoded microspheres with probe DNA (SFEM-p-DNA)

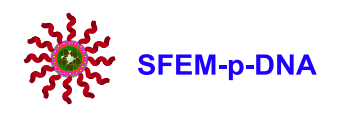

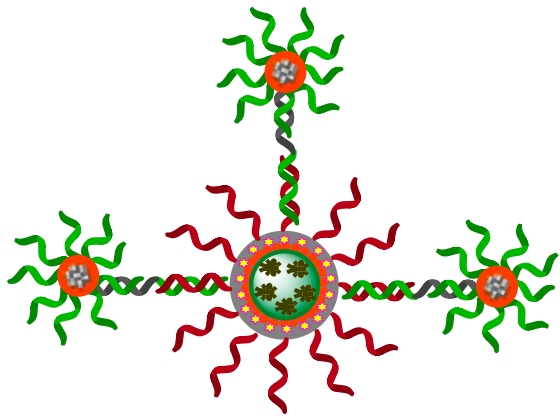

Magnetic assembly for t-DNA detection

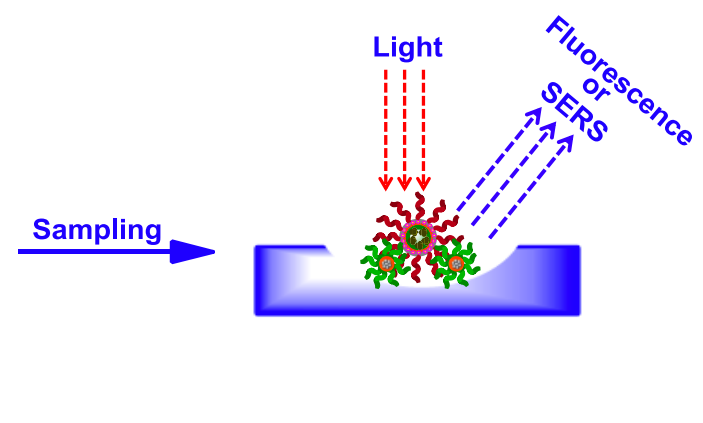

Target DNA

Magnet

Scheme 2 (a) The formation of the magnetic assemblies by SFEM-p-DNA and Mag-c-DNA at the present of target DNA (t-DNA); (b) The detection procedure for t-DNA based on the sandwich hybridization process.

One system in Table 1 was examined to show the detections of the target DNA (I) ATGGTGTAGTAGGTATATTGACTTTCGGTT. The result was presented in Figure 7. According to the result of system I in Figure 7(a), the characteristic fluorescence signals of FITC (emission at 520 $\mathrm{nm}$ ) and PHB (emission at $572 \mathrm{~nm}$ ) were detected, and the characteristic SERS signals of DTNB and HBT were detected as well in Figure 7(a'). These results when compared with those in Figure 7(c) and (c'), showed that the detected fluorescence and SERS spectra agreed with those of original SFEM. The experimental results clearly showed that the fluorescence and SERS signals resulting from the encoded microspheres $\mathrm{MF}(\mathrm{FITC}-\mathrm{PHB}) / \mathrm{Ag}(\mathrm{HBT}-\mathrm{DTNB}) / \mathrm{Ag} / \mathrm{SiO}_{2}$ were detected in the presence of the target DNA (I), while for the non-complementary DNA in the control experiment, negligible signal was detectable (Figure 7(b) and (b')). To confirm the capability of the encored 
microspheres for the specific detection of the DNAs, the system II and system III were carried out for the detections of the target DNA (II) and (III), respectively. The detected fluorescence and SERS characterization of the sandwich complexes derived from target DNA (II) and (III) were also detected (Figure S6 and Figure S7). It could be observed that each fluorescence and SERS spectrum displayed unique fluorescence and SERS signal corresponding to the encoded microspheres only with the existence of complementary t-DNA. Thus, the specific t-DNA could be easily and distinctively identified according to the unique fluorescence and SERS spectra of the SFEM. Therefore, these detection systems hold great potential for superb specific and selective detection of biomolecules in complex biological systems. It is believed that this work will significantly advance the research of encoding technology for specific application in multiplex bioassays.
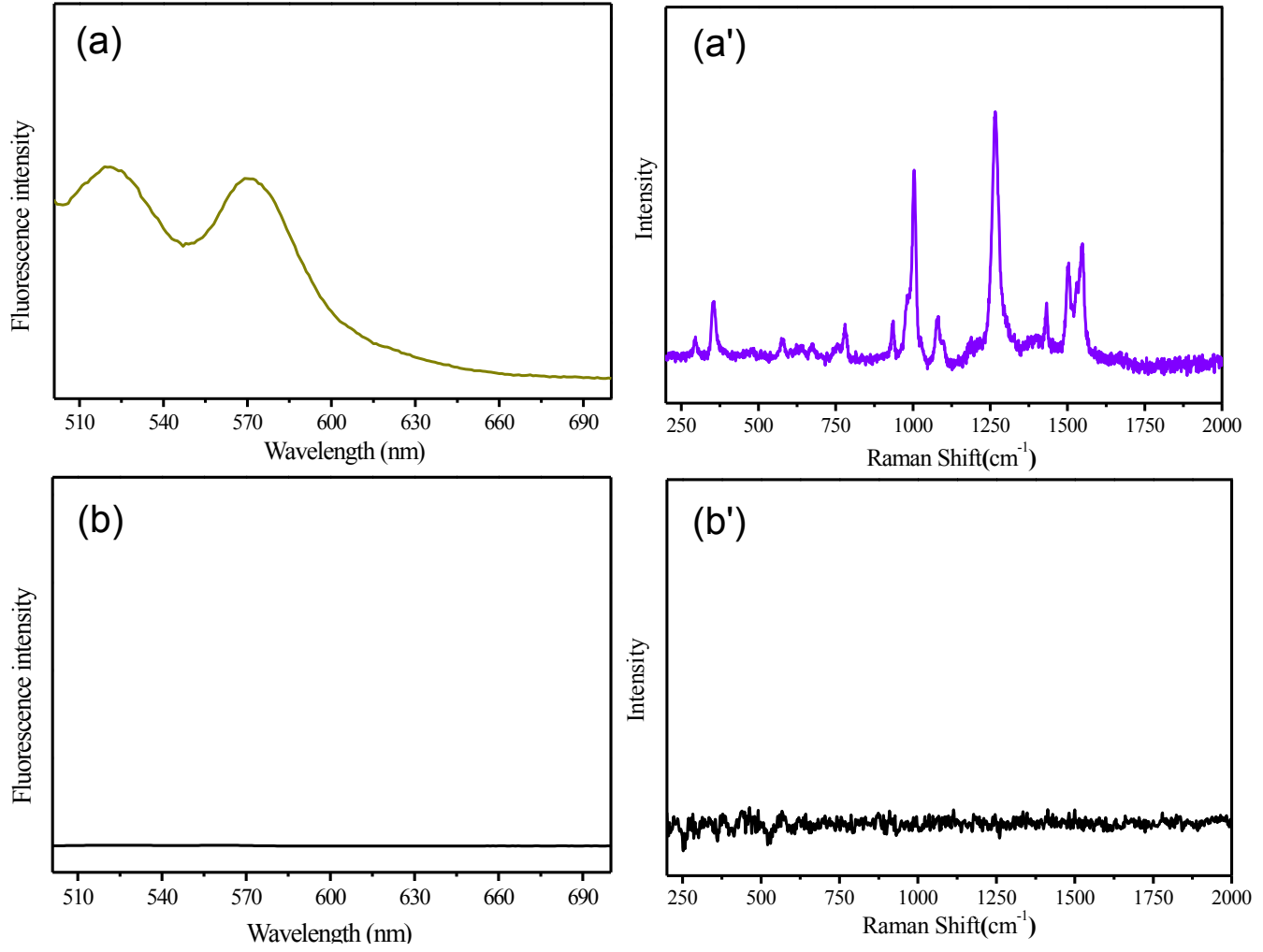

Figure 7 Fluorescence spectra (a) and SERS spectra (a') of the sandwich hybridization detection based on system I (in table 1); Fluorescence spectra (b) and SERS spectra (b') of the control experiment.

\section{Conclusions}


A dual-mode spectroscopic encoded microspheres system based on the combination of fluorescence and SERS spectra encoding was designed and applied for specific DNA detection. Based on the as-prepared MRM/Ag-NPs composite microspheres, SERS reporters and fluorescent probes were fixed in different layers of the microspheres through a controllable and straight forward approach. By taking the fluorescence and SERS spectra in two optical channels to avoid spectral overlaps, the decoding processes were straight for a large pool of SFEM probes. Compared with sole fluorescence or SERS spectra encoding, the combination of fluorescence and SERS spectra increased the encoding capacity dramatically and made a much feasible and controllable encoding process. After the preparation, the encoded microspheres system was applied for specific DNA detection through sandwich bioassay. The distinct and strong fluorescence and SERS spectra signals indicated the encoded microspheres showed high performance for specific DNA detection. We expected that this encoded microsphere method to be general in scope and could be applied to multitude of bioassays for a wide variety of applications.

\section{Acknowledgments}

This work was supported by National Science Foundation of China (Grant No. 51503040, 51603042, 51633001) and State Key Project of Research and Development (Grant No. 2016YFC1100300).

\section{References}

[1] R. Wilson, A. R. Cossins, D. G. Spiller, Angew. Chem. Int. Ed. 45 (2006) 6104-6117.

[2] S. Rauf, A. Glidle, J. M. Cooper, Adv. Mater. 21 (2009), 4020-4024.

[3] Y. Gao, W. L. Stanford, W. C. Chan, Small 7 (2011), 137-146.

[4] Z. Zhang, Y. Long, J. Pan, X. Yan, J. Mater. Chem. 20 (2010), 1179-1185. 
[5] C. N. Allen, N. Lequeux, C. Chassenieux, G. Tessier, B. Dubertret, Adv. Mater. 19 (2007), $4420-4425$.

[6] G. Wang, Y. Leng, H. Dou, L. Wang, W. Li, X. Wang, K. Sun, L. Shen, X. Yuan, J. Li, K. Sun, J. Han, H. Xiao, Y. Li, ACS Nano 7 (2013), 471-481.

[7] K. Cedequist, S. Dean, C. Keating, WIREs Nanomed Nanobiotechnol. 2 (2010), 578-600.

[8] R. E. Gerver, R. Gomez-Sjoberg, B. C. Baxter, K. S. Thorn, P. M. Fordyce, C. A. Diaz-Botia, B. A. Helms, J. L. DeRisi, Lab on a Chip 12 (2012), 4716-4723.

[9] N. H. Finkel, X. Lou, C. Wang, L. He, Anal. Chem. 76 (2004), 352A-359A.

[10] X. Li, T. Wang, J. Zhang, D. Zhu, X. Zhang, Y. Ning, H. Zhang, B. Yang, ACS Nano 4 (2010), 4350-4360.

[11] A. Trojanowska, N. Pazos-Perez, C. Panisello, T. Gumi, L. Guerrini, R. A. Alvarez-Puebla, J. Colloid Interf. Sci. 460 (2015), 128-134.

[12] F. Zhang, R. C. Haushalter, R. W. Haushalter, Y. Shi, Y. Zhang, K. Ding, D. Zhao, G. D. Stucky, Small 7 (2011), 1972-1976.

[13] H. H. Gorris, R. Ali, S. M. Saleh, O. S. Wolfbeis, Adv. Mater. 23 (2011), 1652-1655.

[14] J. Raez, D. R. Blais, Y. Zhang, R. A. Alvarez-Puebla, J. P. Bravo-Vasquez, J. P. Pezacki, H. Fenniri, Langmuir 23 (2007), 6482-6485.

[15] T. Song, J. Q. Liu, W. B. Li, Y. H. Li, X. Gong, L. X. Xuan, J. Chang, ACS Appl. Mater. Interfaces 6 (2014), 2745-2752.

[16] X. Zhang, Y. Xiao, L. He, Y. Zhang, J. Org. Chem. 79 (2014), 6315-6320.

[17] Q. Yang, Y. Li, T. Song, J. Chang, J. Mater. Chem. 22 (2012), 7043-7049.

[18] Y. Zhao, H. C. Shum, H. Chen, L. L. A. Adams, Z. Gu, D. A. Weitz, J. Am. Chem. Soc. 133 (2011), 8790-8793.

[19] P. Yang, Q. Z. Xu, S. Y. Jin, Y. Zhao, Y. Lu, X. W. Xu, S. H. Yu, Chem. Eur. J. 18 (2012), 1154-1160.

[20] Z. L., Zhang, Y. Long, J. B. Pan, X. M. Yan, J. Mater. Chem. 20 (2010), 1179-1185.

[21] Q. H. Liu, J. Liu, J. C. Guo, X. L. Yan, D. H. Wang, L. Chen, F. Y. Yan, L. G. Chen, J. Mater. Chem. 19 (2009), 2018-2025. 
[22] Z. L. Zhang, Y. Q. Wen, Y. Ma, J. Luo, L. Jiang, Y. L. Song, Chem. Commun. 47 (2011), 7407-7409.

[23] J. M. Li, W. F. Ma, L. J. You, J. Guo, J. Hu, C. C. Wang, Langmuir 2013, 29, 6147-6155.

[24] R. Wilson, D. G. Spiller, Angew. Chem. Int. Ed. 45 (2006), 6104-6117.

[25] X. Niu, H. Chen, Y. Wang, W. Wang, X. Sun, L. Chen, ACS Appl. Mater. Interfaces 6 (2014), 5152-5160.

[26] F. Zou, H. Zhou, T. Tran Van, J. Kim, K. Koh, J. Lee, ACS Appl. Mater. Interfaces 7 (2015), 12168-12175.

[27] Z. Wang, S. Zong, W. Li, C. Wang, S. Xu, H. Chen, Y. Cui, J. Am. Chem. Soc. 134 (2012), 2993-3000.

[28] L. You, Q. An, J. Guo, J. J. Hub, C. C. Wang, RSC Adv., 3 (2013), 17469-17476.

[29] R. M. Li, Y. Y. Zhang, J. Tan, J. X. Wan, J. Guo, C. C. Wang, ACS Appl. Mater. Interfaces 8 (2016), 9384-9394.

[30] G. Burcu, H. B. Ismail, T. Ugur, C. P1nar, Analyst 137 (2012), 202-208.

[31] S. Wang, W. X. Xie, X. Zhang, X. Zou, Y. Zhang, Chem. Commun. 48 (2012), 5907-5909.

[32] W. F. Ma, S. Xu, J. M. Li, J. Guo, Y. Lin, C. C. Wang, J. Polym. Sci., Part A: Polym. Chem. 49 (2011), 2725-2733.

[33] Z. L. Zhang, Y. Q. Wen, Y. Ma, J. Luo, L. Jiang, Y. L. Song, Chem. Commun. 47 (2011), 7407-7409. 


\section{Graphical abstract}

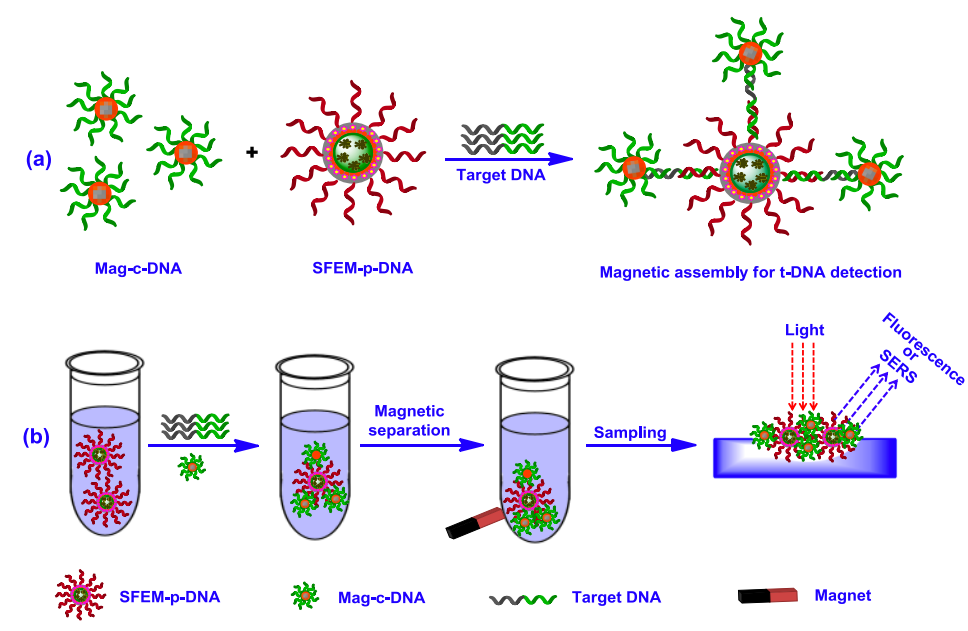

A dual-mode spectroscopic encoded microspheres system based on the combination of fluorescence and SERS spectra encoding was designed and applied for specific DNA detection, which appears to be general in scope for multiplex bioassays of a variety of biomolecules. 